Research Paper:

\title{
Effects of Althaea Root Extract on Alleviating Chemother- apy-Induced Stomatitis Pain: A Randomized Controlled Clinical Trial
}

\author{
Mohamad Sadegh Ghorbani' ${ }^{1}$, Mohsen Taghadosi ${ }^{*}$ (D), Arshia Shariat ${ }^{2}$, Hossein Akbari $^{3}$ (D) \\ 1. Department of Medical Surgical Nursing, Faculty of Nursing \& Midwifery, Kashan University of Medical Sciences and Health Services, Kashan, Iran . \\ 2. Department of Medical Surgical Nursing, School of Nursing and Midwifery, Tehran University of Medical Sciences, Tehran, Iran. \\ 3. Department of Epidemiology \& Biostatistics, Faculty of Health, Kashan University of Medical Sciences and Health Services, Kashan, Iran.
}

\begin{tabular}{|l|l|l|}
\hline $\begin{array}{l}\text { Use your devic to scan } \\
\text { and read the article online }\end{array}$ & $\begin{array}{l}\text { Atation Ghorbani, M. S., et al., 2018. Effects of Althaea Root Extract on Alleviating Chemotherapy-Induced Stomatitis Pain: } \\
\text { A Randomized Controlled Clinical Trial. Journal of Client-Centered Nursing Care, 4(1), pp. 37-44. https://doi.org/10.32598/ } \\
\text { jccnc.4.1.37 }\end{array}$ \\
doi: $:$ https://doi.org/10.32598/jccnc.4.1.37
\end{tabular}

Funding: See Page 43

(c) Copyright: The Author(s)

Article info:

Received: 10 Jun 2017

Accepted: 15 Oct 2017

Available Online: 01 Feb 2018

Keywords:

Chemotherapy, Stomatitis, Mouthwash, Althaea, Pain

\begin{abstract}
A B S T RA C T
Background: Stomatitis as one of the serious side effects of chemotherapy is associated with multiple problems and worse of all failure of cancer treatment. This study aims to investigate the effect of hydroalchoholic extract of the Althaea root in the treatment of stomatitis pain related to chemotherapy.

Methods: This triple-blind clinical trial was carried out on 50 cancer patients with chemotherapyinduced stomatitis and oral pain, who referred to the Oncology Centre of Shahid Beheshti Hospital, Kashan, Iran. The control group was treated with $15 \mathrm{~mL}$ of routine mouthwash solution four times a day for 14 days, whereas the experimental group was treated with half of routine mouthwash solution combined with Althaea root extract (50.50). The severity of stomatitis pain was evaluated using Visual Analog Scale at the baseline, and then 7 and 14 days after the study. The obtained data were analyzed using the Chi-square test, Fisher's exact test, Independent $t$ test, and repeated measures ANOVA in SPSS-PC V. 19.
\end{abstract}

Results: At the base line, the mean score of oral pain in the control group was 4.28(1.39), which reduced to $2.36(1.18)$ and $1.60(1.15)$ on the $7^{\text {th }}$ and $14^{\text {th }}$ day, respectively after the intervention. In the experimental group, the mean score of oral pain was 4.36(1.70) at the baseline which reduced to $2.72(1.67)$ on the $7^{\text {th }}$ day and $1.12(1.56)$ on the $14^{\text {th }}$ day $(\mathrm{P}=0.02$, for the two groups, and in three different time points). The results showed that the reduction of the severity of stomatitis pain was statistically significant in the experimental group compared with the control group $(\mathrm{P}<0.05)$.

Conclusion: Althaea root extract can be used as a suitable and safe mouthwash for relief of stomatitis oral pain in patients undergoing chemotherapy.

\section{* Corresponding Author:}

Mohsen Taghadosi, PhD

Address: Department of Medical Surgical Nursing, Faculty of Nursing \& Midwifery, Kashan University of Medical Sciences and Health Services, Kashan, Iran Tel: +98 (913) 3634439

E-mail: taghadosi_m@kaums.ac.ir 


\section{Background}

tomatitis or oral mucositis is a serious and debilitating side effect of chemotherapy. Patients with stomatitis suffer from symptoms, such as dry mouth, erythema, edema, painful bleeding wounds, infection (secondary or systemic), and altered sense of taste (Yayla et al. 2016; Kooshyar et al. 2017, Silva et al. 2017). The incidence of oral mucositis is reported to be $15 \%-90 \%$ overall among patients (Dutta \& Garg 2016).

The main cause of stomatitis is unclear but probably due to increased levels of prostaglandins, anti-metabolites, free radicals, anti-tumor antibiotics, and factors such as $\beta$-type interleukin- 1 and tumor necrosis factor $\alpha$ (Kooshyar et al. 2017). Stomatitis is more frequently seen in medication regimens, such as cytarabine, Fluorouracil (5-FU), etoposide, doxorubicin, cisplatin, cyclophosphamide, paclitaxel and actinomycin (Avritscher, Cooksley \& Elting 2004; Alijani Renani et al. 2012). Stomatitis not only causes discomfort for the patient by inducing pain (prevalence rate of $76 \%$ to $86 \%$ ) (Mansouri et al. 2016), but may also interfere in receiving food and liquids (Eslami et al. 2016), and ends in malnutrition, dehydration, fatigue, weakness, weight loss, nausea, vomiting and even aspiration (Eilers \& Million 2007).

The outcome of these complications is prolonged hospitalization and special care, such as intravenous infusion, parenteral nutrition, and administration of opioids and barbiturates (Lalla et al. 2008; Gupta and West 2016). Severe stomatitis may lead to reduction in the chemotherapy drug dose, discontinuation of treatment, the patient's refusal of further treatment, treatment failure, increased costs, reduced quality of life, and even life-threatening problems (Pavesi et al. 2011; Ala et al. 2016; Charantimath 2016; Silva et al. 2017). Because there is a relationship between the mouth and dreams, sexual communication, talking, social activities, sleeping and nutrition; maintenance of oral health is of particular importance (Shabanlouei et al. 2006).

Nowadays, different strategies such as management of local or systemic pain (using paracetamol, non-steroidal anti-inflammatory drugs, or opioids) (Dutta \& Garg 2016); bleeding control and debridement of mouth sores; oral hygiene and mouthwashes; antacids containing diphenhydramine, nystatin, prostaglandin E; psychotherapy (Ashktorab et al. 2010; Brunner 2010, Miranzadeh et al. 2014; Eslami et al. 2016); cryotherapy and low-level lasers are used to alleviate stomatitis pain and healing of oral ulcers (Pavesi et al. 2011; Gupta \& West 2016). Most of these treatments have no significant results and sometimes even cause side effects (Barahimi et al. 2006; Charantimath 2016).

One of the treatments is herbal medicines, used for the treatment of various diseases since ancient times. Althaea officinalis-L, is one of the most important medicinal mucilaginous herbs and of the Malvaceae family. This plant which is commonly known as Althaea (Khatmi in Persian), is distributed worldwide (Benbassat et al. 2014). All parts of this plant (leaves, flowers, and roots) have medicinal properties (Al-Snafi 2013; Dehghan, Dashti \& Baghizadeh 2013). Althaea root (sodden, or its extract) is used in fever, swelling of the lining of the mouth, dry throat, gastric ulcer, bronchitis, wound healing and skin irritation.

Well-known compounds of roots include flavonoids, polysaccharides and mucin. Polysaccharides in Althaea root have antioxidant and anti-inflammatory properties, stimulating the immune system. Polysaccharides and flavonoids in Althaea root have antiplatelet, anti-inflammatory, antibacterial and anti-tumour effects (Shah et al. 2011; Al-Snafi 2013; Ghavi 2015).

Jafari Manesh et al. (2015) reported the effect of aqueous extracts of the Althaea flower and root on reduction of the symptoms of hand skin allergy caused by latex. On the other hand, Motaharinia showed that the Althaea flower and root extract has less antifungal effect on Malassezia furfur compared with ketoconazole (Motaharinia et al. 2011). Shah et al. (2011) reported the antimicrobial and anti-inflammatory activities of ethanol extract of Althaea root.

One of the most effective treatments is the use of mouthwash. Chemical mouthwashes have side effects, such as brown staining of the teeth, changes in sense of taste and bitter taste, and due to a weakened immune system, it is difficult for the patient to tolerate the irritation caused by chemical mouthwash. It sometimes leads to ulcers and exacerbation of bleeding (Tobias et al. 2010). Nowadays, herbal mouthwashes are of great interest due to their low complications (Alijani Renani et al. 2012).

We observed that some patients used Althaea (flower or root) to alleviate and heal their oral ulcers. Considering the lack of effective treatment as well as no clinical studies on the treatment effects of Althaea on stomatitis, the present study aimed to determine the effect of 
mouthwash containing hydro-alcoholic extract of Althaea root on the alleviation of stomatitis pain.

\section{Materials and Methods}

This triple-blind clinical trial was conducted on cancer patients with chemotherapy-induced stomatitis (grades 1-3), who were referring to the Oncology Ward of Shahid Beheshti Hospital, Kashan, Iran, in 2016. The patients, nurses who gave mouthwash to the patients and the statistician who performed the data analysis were blinded to the study and intervention outcomes.

The inclusion criteria of the study samples were as follows: undergoing chemotherapy without simultaneous radiation therapy; suffering from stomatitis (with grades $1-3$ ); being $\geq 20$ years old; having complete consciousness; willing to participate in the study; lacking any known underlying disease (kidney, liver, and immune deficiency); lacking any known hypersensitivity (asthma, rhinitis, and allergies); and not receiving systemic antibiotics and antifungal drugs at the start of the study.

The exclusion criteria were as follows: receiving radiation therapy during chemotherapy; developing fever; leaving the study; irregular using of the mouthwash in terms of time and amount; and receiving systemic antibiotic or antifungal drugs during the study or using another mouthwash during the study.

The sample size was calculated according to the sample size formula and parameters were derived from the previous study conducted on the same topic (Barahimi et al. 2006), (a type I error of 5\% and a type II error of $10 \%$, the recovery rate in the experimental group was $31 \%$ $\left[p_{1}\right]$, whereas that in the control group was $20 \%\left[p_{2}\right]$, and considering the maximum difference of $35 \%$ in rate of recovery between two groups). A 50-subject sample size (25 in each group) was estimated for the study.

$$
\begin{aligned}
n & =\frac{\left(z_{1}-\frac{a}{2}+z_{1}-\beta\right)^{2}\left(p_{1}\left(1-p_{1}\right)\right)+p_{2}\left(1-p_{2}\right)}{\left(p_{1}-p_{2}\right)^{2}} \\
& =\frac{(1.96+0.9)^{2}(0.31(1-0.31))+0.20(1-0.20)}{(0.35)^{2}}=25
\end{aligned}
$$

At the beginning of the study, all patients were divided into experimental and control groups, using permuted block randomization (Figure 1).

\section{Intervention}

The control group received the Oncology Ward's routine mouthwash. Approximately $100 \mathrm{~mL}$ of the routine mouthwash contained $5 \mathrm{~mL}$ (100 mg) of $2 \%$ lidocaine, 2
$\mathrm{mL}(8 \mathrm{mg})$ of dexamethasone, $3 \mathrm{mg}(1500 \mathrm{mg})$ of sucralfate, $30 \mathrm{~mL}$ (75 mg) of diphenhydramine syrup, and 60 $\mathrm{mL}(5400 \mathrm{mg})$ of Aluminum-Magnesium-simethicone (Al-Mg-s) syrup, lidocaine ampoule, nystatin drops, $\mathrm{Al}-\mathrm{Mg}-\mathrm{S}$, and diphenhydramine syrup (purchased from Exir Co. Emad Darman Pars Co., Soha Co., and Alhawi Co., Tehran, Iran).

The experimental group received a combination of half of the routine mouthwash and Althaea root extract with a concentration of $8 \%$ (50.50). Approximately $100 \mathrm{~mL}$ of this solution contained $2.5 \mathrm{~mL}(50 \mathrm{mg})$ of $2 \%$ lidocaine, $1 \mathrm{~mL}$ (4 mg) of dexamethasone, $1.5 \mathrm{~mL}$ (750 mg) of sucralfate, $15 \mathrm{~mL}$ (37.5 mg) of diphenhydramine syrup, 30 $\mathrm{mL}(2750 \mathrm{mg}$ ) of Al-Mg-S syrup, and $50 \mathrm{~mL}$ of Althaea root extract. Mouthwashes with the same ratio reached the final volume of $840 \mathrm{~mL}$ (for 14 days of use) and then poured into identical dark bottles, in terms of shape and size, which were labeled by a special code.

After confirmation by a botanist and drying in the shade, Althaea root was milled into powder form by Barij Essence Pharmaceutical Company, Kashan, Iran. The powder was poured into a percolator after being wetted with solvent ( $96 \%$ ethanol). Subsequently, 96\% ethanol was added to it to receive a 1:1 ratio after 48 hours. Its solvent was isolated as much as possible by a condenser under vacuum. It was then placed in front of airflow in wide trays so that the solvent was completely evaporated and turned into dried extract. The extracted powder was sterilized by ultraviolet radiation and then poured into a dark bottle, and maintained at $4{ }^{\circ} \mathrm{C}$ until further use. The extraction ratio of the extract and root powder was $8 \%$ (Jafari Manesh et al. 2015).

In this study, researchers using face-to-face training methods educated patients in both study groups were separately with the oral care procedure and the use of toothbrushes and mouthwash. The patients were trained to wash their hands four times a day; after breakfast, lunch, dinner, and before bedtime, clean their teeth with a soft toothbrush and a gentle toothpaste, and gargle 15 $\mathrm{mL}$ of the mouthwash solution every time for three minutes (kept the solution in their mouth and then poured it out) within 14 days.

The patients were requested not to wash their mouth and eat anything until 1 hour after rinsing with the mouthwash. To ensure the proper implementation of the mouthwash, patients or their companions were trained to mark a check sheet (consisting of 14 rows [days] and four columns [four times a day]). According to the check sheets, if the participant did not comply with the treat- 

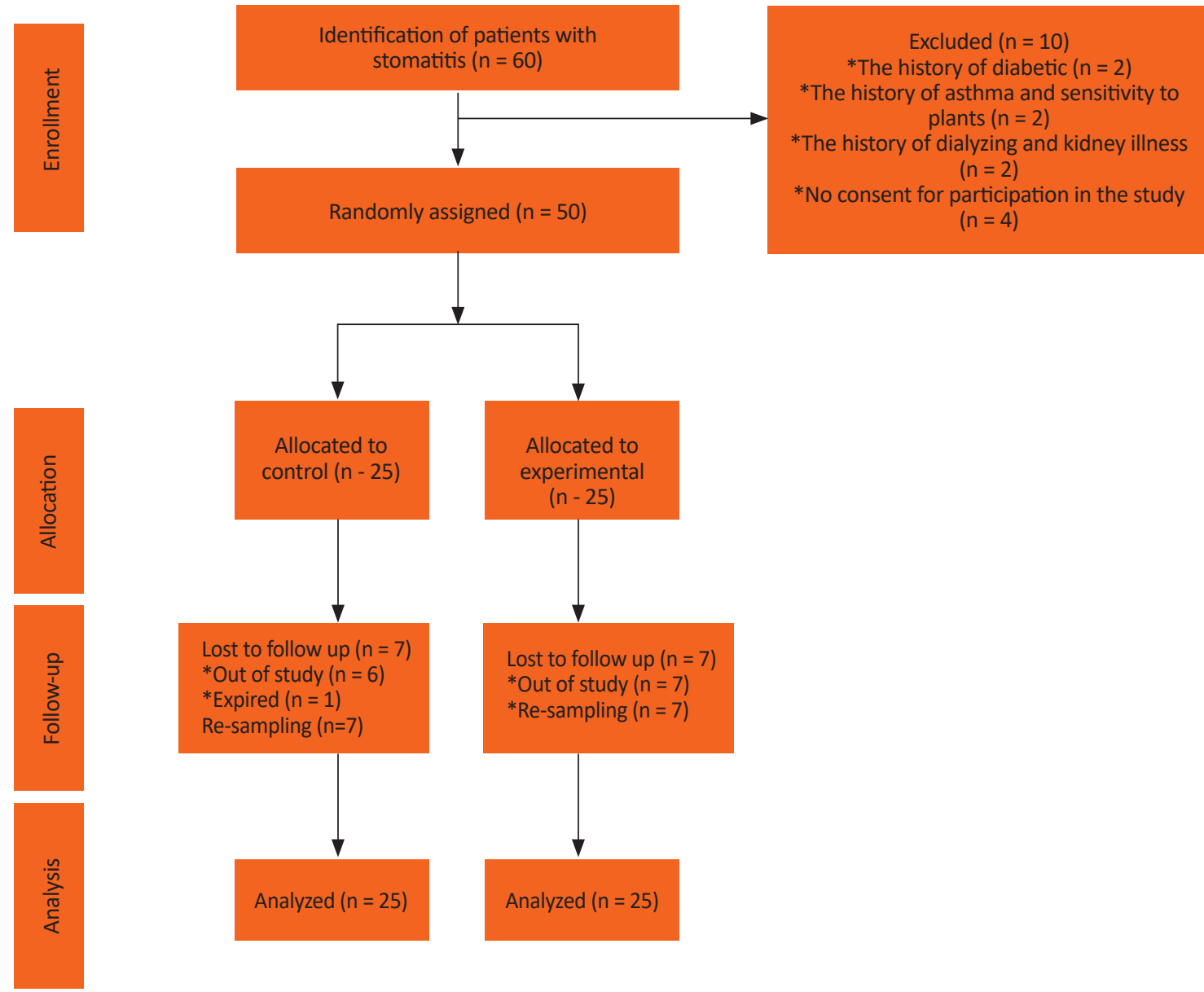

Figure 1. Consort flow

Client- Centered Nursing Care

ment protocol, he or she would be excluded from the study. The patients were requested to return the bottle into the refrigerator after every rinse.

\section{Data collection}

The data collection instrument had two parts. The first part included the patient's demographic information (age, sex, marital status, education level, occupation) and questions about the duration of cancer, chemotherapy information (type and number of cycles before intervention), receiving an analgesic and artificial teeth. The second part consisted of the checklist to record the severity of oral pain, based on Visual Analog Scale (VAS) self-reported criteria.

VAS is a standard tool for measuring pain intensity. This instrument is a $10-\mathrm{cm}$ ruler in which 0 shows no pain and 10 represents intolerable pain (Epstein \& Schubert 2004). VAS is a quick, simple, stable, and valid tool that has been used in many investigations and medical trials (Mohseni Bandpei et al. 2012). The validity and reliability of this instrument have also been confirmed in previous studies (Hojjati et al. 2012; Sharif Nia et al 2017). Patients' oral pain were assessed by the researcher in the first, $7^{\text {th }}$ and $14^{\text {th }}$ days using a flashlight, tongue blade, and swaps; a checklist of stomatitis severity and oral pain intensity was also completed.

The study goals were explained to all study patients and their written consent was obtained. All patients were free to participate or leave the study and their treatment information was held confidential. They were also aware that in accordance with the principles of the Declaration of Helsinki, punishment will be considered in the case of disclosure of patient's information by the researchers.

\section{Data analysis}

The data were analyzed by SPSS-PC, V. 19. To compare two groups, the Chi-square and Fisher exact tests were used for qualitative data. To determine the normal distribution of variables, we used the Kolmogorov-Smirnov test, that approved the normality of the quantitative data. The analyses were conducted based on the intention-totreat approach. The Independent $t$ test was used for com- 
parison of mean scores between the two groups. Finally, repeated measures ANOVA were used to analyze the effect of time and treatment groups on changes in pain severity. $\mathrm{P}<0.05$ was considered significant.

\section{Results}

A total of 50 patients participated in the study. The Mean (SD) age in the control and experimental groups was 49.48(16.80) and 53.96(15.48) year, respectively. There was no significant difference between the two groups in terms of age, sex, marital status, level of education, dentures, duration of disease, number and type of chemotherapy, and cancer type $(\mathrm{P} \geq 0.05)$ (Table 1$)$.

At the baseline, the mean score of stomatitis oral pain in the experimental group was 4.36(1.70), which dropped to $2.72(1.67)$ on the 7 th day and $1.12(1.56)$ on the 14 th day after the intervention. In the control group, the mean score of stomatitis oral pain was 4.28(1.39), which reduced to $2.36(1.18)$ on the $7^{\text {th }}$ and $1.60(1.15)$ on the $14^{\text {th }}$ day after the intervention $(\mathrm{P}<0.05)$ (Table 2$)$.

Comparison of the mean score of oral pain severity between two groups (with Independent $t$ test) showed no significant statistical difference between two groups before the intervention and the $7^{\text {th }}$ day after it in terms of oral pain severity $(\mathrm{P} \geq 0.05)$, but a statistically significant difference was observed on the $14^{\text {th }}$ day $(\mathrm{P}<0.05)$ (Table 2$)$.

Repeated measures ANOVA showed a significant difference between two groups in terms of the mean score of oral pain $(\mathrm{P}<0.05)$. Moreover, the interaction effect of time and group showed that oral pain between two groups changed over time. In other words, changes in the severity of oral pain were not similar in both groups, and a reduction in severity of oral pain was statistically significant in the experimental group compared with the control group $(\mathrm{P}<0.05)$ (Table 2) (Figure 2).

\section{Discussion}

This study compared the effect of mouthwash containing hydroalcoholic extract of Althaea root with the current oncology routine mouthwash on alleviating stomatitis-induced oral pain. The severity of oral pain showed a further decrease in the experimental group, which used the mouthwash containing Althaea root extract compared with the control group with the routine mouthwash. However, Althaea root extract-contained solution composed half of the component of the routine solution.

Valiei observed the inhibitory effect of hexane extract of Althaea root on a number of Gram-positive and Gramnegative bacteria and oral fungus (Valiei, Shafaghat \&

Table 1. Demographic and clinical characteristics of patients undergoing chemotherapy referred to Shahid Beheshti Hospital

\begin{tabular}{|c|c|c|c|c|c|}
\hline \multirow{2}{*}{\multicolumn{3}{|c|}{ Variable }} & \multicolumn{2}{|c|}{ No. (\%) } & \multirow{2}{*}{$\mathbf{P}$} \\
\hline & & & Experimental & Control & \\
\hline \multirow{3}{*}{ Gender } & \multirow{2}{*}{\multicolumn{2}{|c|}{ Male }} & $11(44)$ & $11(44)$ & \\
\hline & & & & & $0.99^{1}$ \\
\hline & \multicolumn{2}{|c|}{ Female } & $14(56)$ & $14(56)$ & \\
\hline \multirow{3}{*}{ Marital status } & \multirow{2}{*}{\multicolumn{2}{|c|}{ Married }} & $23(92)$ & $18(72)$ & \\
\hline & & & & & $0.182^{2}$ \\
\hline & \multicolumn{2}{|c|}{ Single, widow, divorced } & $2(8)$ & $7(28)$ & \\
\hline \multirow{2}{*}{ Education level } & \multirow{2}{*}{$\begin{array}{l}\text { Highest year of school } \\
\text { completed }\end{array}$} & $\leq 9$ Years & $15(60)$ & $14(56)$ & \multirow{2}{*}{$0.774^{1}$} \\
\hline & & $\geq 10$ Years & $10(40)$ & $11(44)$ & \\
\hline \multirow{3}{*}{ Artificial teeth } & \multicolumn{2}{|c|}{ Yes } & $13(52)$ & $8(32)$ & \multirow{3}{*}{$0.087^{1}$} \\
\hline & \multirow{2}{*}{\multicolumn{2}{|c|}{ No }} & & & \\
\hline & & & $12(48)$ & $17(68)$ & \\
\hline \multicolumn{3}{|c|}{ Age, Mean (SD), y } & $53.96(15.48)$ & $49.48(16.80)$ & $0.332^{3}$ \\
\hline \multicolumn{3}{|c|}{ Duration of cancer, morbidity, Mean (SD) , y } & $7.96(7.02)$ & $9.72(13.48)$ & $0.565^{3}$ \\
\hline \multicolumn{3}{|c|}{ Chemotherapy cycles, Mean (SD) course } & $7.48(6.24)$ & $7.04(5.53)$ & $0.792^{3}$ \\
\hline
\end{tabular}

1: Chi-square test; 2: Fisher exact test; 3 : Independent $t$ test 
Table 2. Comparing the mean and standard deviation of stomatitis and oral pain severity in both groups of cancer patients undergoing chemotherapy referred to Shahid Beheshti Hospital, Kashan, in 2016

\begin{tabular}{|c|c|c|c|c|c|}
\hline \multirow{2}{*}{ Assessment Time } & \multicolumn{2}{|c|}{ Mean (SD) } & \multirow{2}{*}{$P_{1}$} & \multicolumn{2}{|r|}{$P_{2}$} \\
\hline & Experimental & Control & & Time Effect & Time \& Group Effect \\
\hline Base line & $4.36(1.70)$ & 4.28 (1.39) & 0.623 & & \\
\hline $7^{\text {th }}$ day & $2.72(1.67)$ & $2.36(1.18)$ & 0.736 & 0.001 & 0.02 \\
\hline $14^{\text {th }}$ day & $1.12(1.56)$ & $1.60(1.15)$ & 0.34 & & \\
\hline
\end{tabular}

1: Independent $t$ test; 2 : Repeated measures analysis of variance

Client- Centered Nursing Care

Salimi 2011). Shah et al. have reported the inhibitory effect of ethanol extract of Althaea root on adenovirus, coxsackie virus $\mathrm{B}_{2}$, herpes virus Type 1 , polio virus, measles virus, Semlicki Forest virus and Mycobacterium tuberculosis (Shah et al. 2011).

Flavonoids and polysaccharides found in Althaea root have confirmed antioxidant, anti-inflammatory, antiallergic, antibacterial, and antiviral effects (Zoobi \& Mohd 2011; Sathishkumar et al. 2008). Polyphenolic compounds (flavonoids) found in Althaea root exert their inhibitory effects on bacterial growth by producing hydrogen peroxide, which probably reduces oral microbial load (Dehghan, Dashti \& Baghizadeh 2013).

This reduction may be due to reduced microbial load, inflammation and irritation of the oral cavity caused by the protective effect of compounds (flavonoids, polysaccharides and pectin) found in Althaea. Jafari Manesh et al. (2015) showed that Althaea extract (root and flower) reduced the symptoms of skin sensitivity to materials containing latex in the experimental group.
Al-Snafi (2013) reported the anti-inflammatory, analgesic and anti-ulcer properties of Althaea root on rats, as well as the positive effect of $20 \%$ ointment containing aqueous extract of the Althaea root on the external ear itching in rabbits.

These effects are due to the fact that the Althaea plant is rich in antioxidants, which can deactivate free radicals, and their protective activity is essential for the body. A total of $69 \%$ of the Althaea antioxidant activity is related to alpha-tocopherol combination (Kardošová \& Machova 2006). It seems that the anti-inflammatory properties of Althaea root are due to the bio-adhesive polysaccharide layer on the surface of inflamed and damaged epithelial lining of the oral mouth, thereby leading to enhanced protection and hydration of oral mucosal tissues against chemical, physical, and biological, and prevents the cellular and regional inflammation (Deters et al. 2010).

The antimicrobial, anti-inflammatory, and protective properties of Althaea root extract might explain some of the results we observed in our experiment. Among herbal plants, Althaea is a well-known plant due to its wide range of therapeutic effects. It has been used for thou-

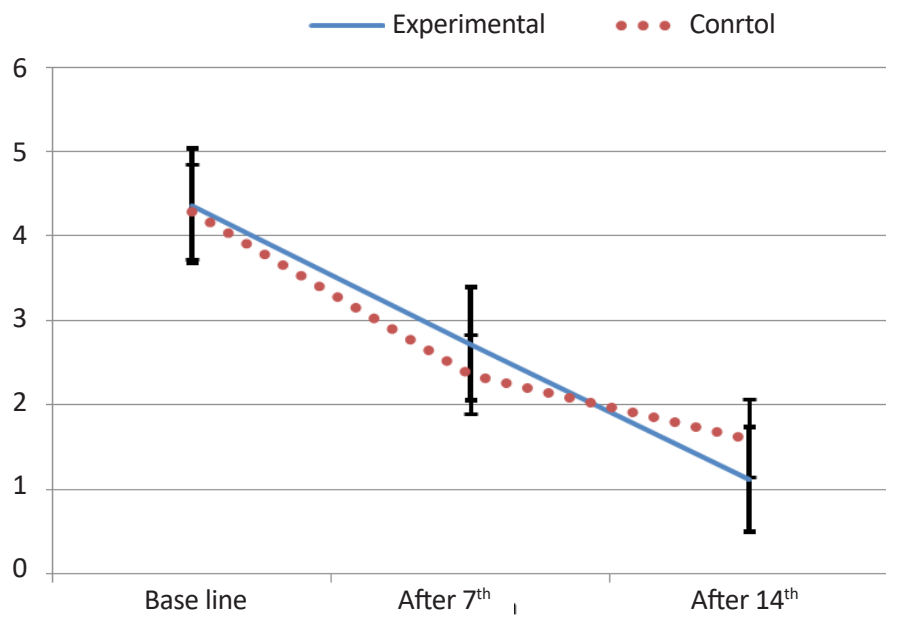

Figure 2. Comparing the mean severity of oral pain during intervention in both groups 
sands of years for the treatment of different disorders, especially wounds, infections, fever, and bronchitis.

Even if we assume that the effect of the two mouthwashes in the treatment of stomatitis pain is equal, the dose of chemical drugs in the mouthwash containing Althaea root extract has been reduced by half in comparison to routine mouthwash so the side effect of these drugs has been reduced as well.

Althaea root extract-contained solution was effective in alleviating of oral pain. The patients, who used this mouthwash, were satisfied with the result of treatment. Toxicity, allergic reactions, or other side effects were not observed upon using this mouthwash during the study. Considering the availability and lower cost of the Althaea plant compared to chemical drugs, this solution is recommended for the alleviation of stomatitis pain along with other existing therapies.

Since the Althaea root extract was combined with the routine solution it is better that the extract is used alone in future studies to reveal the therapeutic effects of Althaea as well. Some limitations of the current study were as follows: the small sample size, inability to control observance of recommendations by patients at home, disregarding other variables such as history of oral disease, and paraclinical parameters such as white blood cells and platelets that could confound the findings of the study. The possibility of false reports by the patients should also be considered.

\section{Ethical Considerations}

\section{Compliance with ethical guidelines}

This study was approved by the Ethics Committee of Kashan University of Medical Sciences under the code of IR.KAUMS.REC1395.10, in May 17, 2016. It was also registered in the Iranian Registry of Clinical Trials (IRCTs) under the number IRCT201307274655N4.

\section{Funding}

This research did not receive any specific grant from funding agencies in the public, commercial, or not-forprofit sectors.

\section{Conflict of interest}

Study design, sampling, data collection and preparing the manuscript: Mohamad Sadegh Ghorbani; Data and statistical analysis: Dr. Hossein Akbari; and Supervising the study: Dr. Mohsen Taghadosi.

\section{Acknowledgements}

Hereby, the authors appreciate the personnel of the oncology and chemotherapy clinics of Shahid Beheshti Hospital, Kashan, for their cooperation, Barij Essence Pharmaceutical Company, especially Dr Hosseini, for the preparation of Althaea root extract, as well as patients who implemented the recommendations with pain tolerance and used the mouthwash.

\section{References}

Ala, S., et al., 2016. Efficacy of sucralfate mouth wash in prevention of 5-fluorouracil induced oral mucositis: A prospective, randomized, double-blind, controlled trial. Nutrition and Cancer, 68(3), pp. 456-63. [DOI:10.1080/01635581.2016. 1153666] [PMID]

Alijani Renani, H., et al., 2012. Effect of chamomile mouthwash to preventing chemotherapy-induced ostomatitis in children. Journal of Mazandaran University of Medical Sciences, 21(86), pp. 19-25.

Al-Snafi, A. E., 2013. The pharmaceutical importance of Althaea officinalis and Althaea rosea: A review. International Journal of PharmTech Research, 5(3), pp. 1387-5.

Ashktorab, T., et al., 2010. [Preventive effects of an oral rinse Peppermint essence on chemotherapy-induced oral mucosistis (Persian)]. Koomesh, 12(1), pp. Pe8-13.

Avritscher, E. B., Cooksley, C. D. \& Elting, L. S., 2004. Scope and epidemiology of cancer therapy-induced oral and gastrointestinal mucositis. Seminars in Oncology Nursing, 20(1), pp. 3-10. [DOI:10.1053/j.soncn.2003.10.002]

Barahimi, N., et al., 2006. [The effect of honey on ostomatitis recovery of patients undergoing chemotherapy in hospitals affiliated to Shaheed Beheshti Medical university (Persian)] Advances in Nursing \& Midwifery, 16(52), PP. 34-9.

Benbassat, N., et al., 2014. Influence of the extraction solvent on antioxidant activity of Althaea officinalis L. root extracts. Central European Journal of Biology, 9(2), pp. 182-8. [DOI:10.2478/ s11535-013-0245-2]

Brunner, L. S., 2010. Brunner \& Suddarth's textbook of medicalsurgical nursing. Philadelphia: Lippincott Williams \& Wilkins.

Charantimath, S., 2016. Use of curcumin in radiochemotherapy induced oral mucositis patients: A control trial study. World Academy of Science, Engineering and Technology, International Journal of Medical, Health, Biomedical, Bioengineering and Pharmaceutical Engineering, 10(3), pp. 147-52.

Dehghan, E., Dashti, H. \& Baghizadeh, A., 2013. [Antibacterial effect of ethanol extract (Althaea officinalis) on Streptococcus pyogenes compared with prevalent antibiotics in-vitro (Persian)]. Journal of Rafsanjan University of Medical Sciences, 12(6), pp. 461-74

Deters, A., et al., 2010. Aqueous extracts and polysaccharides from Marshmallow roots (Althea officinalis L.): Cellular inter- 
nalisation and stimulation of cell physiology of human epithelial cells in vitro. Journal of Ethnopharmacology, 127(1), pp. 62-9. [DOI:10.1016/j.jep.2009.09.050] [PMID]

Dutta, K. \& Garg, R., 2016. Morphine mouth-wash in oral mucositis: A mini re-view. Palliative Medicine and Hospice Care, 2(2), pp. 26-9. [DOI:10.17140/PMHCOJ-2-115]

Eilers, J. \& Million, R., 2007. Prevention and management of oral mucositis in patients with cancer. Seminars in Oncology Nursing, 23(3), pp. 201-12.

Epstein, J. B. \& Schubert, M. M., 2004. Managing pain in mucositis. Seminars in Oncology Nursing, 20(1), pp. 30-7. [DOI:10.1053/j.soncn.2003.10.006]

Eslami, H., et al., 2016. Efficacy of hypozalix spray and propolis mouthwash for prevention of chemotherapy-induced oral mucositis in leukemic patients: A double-blind randomized clinical trial. Journal of Dental Research, Dental Clinics, Dental Prospects, 10(4), pp. 226. [DOI:10.15171/joddd.2016.036] [PMID] [PMCID]

Ghavi, P. P., 2015. The extraction process optimization of antioxidant polysaccharides from Marshmallow (Althaea officinalis L.) roots. International Journal of Biological Macromolecules, 75, pp. 51-7. [DOI:10.1016/j.ijbiomac.2014.11.047] [PMID]

Gupta, A. \& West, H. J., 2016. Mucositis (or stomatitis). JAMA Oncology, 2(10), p. 1379. [DOI:10.1001/jamaoncol.2016.2103] [PMID]

Hojjati, H., et al., 2012. [Comparison the effect of two methods, patient controlled analgesia and intramuscular injection after abdominal surgery in patients admitted to Amiral Momenin hospital in Ahwaz (Persian)]. Medical - Surgical Nursing Journal, 1(2), p. 1-5.

Jafari Manesh, H., et al., 2015. [The effect of alcea althea on latex allergy among operating room staffs in Arak hospitals, Iran (Persian)]. Complementary Medicine Journal of Faculty of Nursing $\mathcal{E}$ Midwifery, 4(4), pp. 954-66.

Kardošová, A. \& Machova, E., 2006. Antioxidant activity of medicinal plant polysaccharides. Fitoterapia. 77(5), pp. 367-73. [DOI:10.1016/j.fitote.2006.05.001] [PMID]

Kooshyar, M. M., et al., 2017. A randomized placebo-controlled double blind clinical trial of quercetin in the prevention and treatment of chemotherapy-induced oral mucositis. Journal of Clinical and Diagnostic Research, 11(3), p. ZC46. [DOI:10.7860/ JCDR/2017/23975.9571]

Lalla, R. V., et al., 2008. Management of oral mucositis in patients who have cancer. Dental Clinics of North America, 52(1), pp. 6177. [DOI:10.1016/j.cden.2007.10.002] [PMID] [PMCID]

Mansouri, P., et al., 2016. The effect of Aloe vera solution on chemotherapy-induced stomatitis in clients with lymphoma and leukemia: a randomized controlled clinical trial. International Journal of Community Based Nursing and Midwifery, 4(2), p. 119. [PMID] [PMCID]

Miranzadeh, S., et al., 2014. A new mouthwash for chemotherapy induced stomatitis. Nursing and Midwifery Studies, 3(3), p. e20249. [DOI:10.17795/nmsjournal20249]

Mohseni Bandpei, M. A., et al., 2012. Shoulder pain and functional disability in Iranian premier league volleyball players. Journal of Mazandaran University of Medical Sciences, 22(90), pp. 95-103.
Motaharinia, Y., et al., 2011. [Comparison of the antifungal effect of licorice root, althoca officinalis extracts and ketoconazole on malassezia furfur (Persian)]. Armaghan-e Danesh, 16(5), pp. 425-32.

Pavesi, V. C., et al., 2011. Healing action of topical chamomile on 5-fluouracil induced oral mucositis in hamster. Supportive Care in Cancer, 19(5), pp. 639-46. [DOI:10.1007/s00520-010-0875-0] [PMID]

Sathishkumar, T., et al., 2008. Optimization of flavonoids extraction from the leaves of Tabernaemontana heyneana wall using L16 Orthogonal design. Nature and Science, 6(3), pp. 10-21.

Shabanlouei, R., et al., 2006. [Effect of chamomile mouthwash in the prevention of chemotherapy-induced stomatitis (Persian)]. Archives of Rehabilitation, 7(2), pp. 70-5.

Shah, S. A., et al., 2011. Pharmacological activity of Althaea officinalis L. Journal of Medicinal Plants Research, 5(24), pp. 5662-6.

Sharif Nia, H., et al., 2017. Effect of acupressure on pain in Iranian leukemia patients: A randomized controlled trial study. International Journal of Nursing Practice, 23(2), p. e12513. [DOI:10.1111/ijn.12513] [PMID]

Silva, F. C., et al., 2017. Nystatin and lidocaine pastilles for the local treatment of oral mucositis. Pharmaceutical Development and Technology, 22(2), PP. 266-74. [DOI:10.1080/10837450.201 6.1221424] [PMID]

Tobias, J. S., et al., 2010. Chemoradiotherapy for locally advanced head and neck cancer: 10-year follow-up of the UK Head and Neck (UKHAN1) trial. The Lancet Oncology, 11(1), pp. 66-74. [DOI:10.1016/S1470-2045(09)70306-7]

Valiei, M., Shafaghat, A. \& Salimi, F., 2011. Chemical composition and antimicrobial activity of the flower and root hexane extracts of Althaea officinalis in Northwest Iran. Journal of Medicinal Plants Research, 5(32), pp. 6972-6.

Yayla, E. M., et al., 2016. Sage tea-thyme-peppermint hydrosol oral rinse reduces chemotherapy-induced oral mucositis: A randomized controlled pilot study. Complementary Therapies in Medicine, 27, pp. 58-64. [DOI:10.1016/j.ctim.2016.05.010] [PMID]

Zoobi, J. \& Mohd, A., 2011. Three new compounds from the roots of Althaea officinalis L. International Journal of Research in Ayurveda \& Pharmacy, 2(3), pp. 864-68. 